\title{
Evaluation of Prescriber Responses to Pharmacist Recommendations Communicated by Fax in a Medication Therapy Management Program (MTMP)
}

\author{
Prasadini N. Perera, MS; Mignonne C. Guy, PhD; Ashley M. Sweaney, PharmD Candidate; \\ and Kevin P. Boesen, PharmD
}

\begin{abstract}
BACKGROUND: As defined by the Medicare Prescription Drug, Improvement, and Modernization Act of 2003, medication therapy management programs (MTMPs) must be designed to decrease adverse drug events and improve patient outcomes by promoting appropriate medication use. WellPoint Inc. contracted with the pharmacist-run University of Arizona College of Pharmacy Medication Management Center (UA MMC) to provide a pilot telephone-based MTMP to approximately 5,000 high-risk beneficiaries from among its nearly 2 million Medicare prescription drug plan (PDP) beneficiaries. Eligibility for the program was determined by a minimum of 2 of 6 chronic diseases (dyslipidemia, cardiovascular disease, depression, diabetes mellitus, congestive heart failure, and chronic obstructive pulmonary disease; at least 1 of the latter 2 diseases must be present), at least 3 Part-D covered medications, and greater than $\$ 4,000$ per year in predicted drug spending. In addition to these criteria, WellPoint Inc. used the Johns Hopkins adjusted clinical groups (ACG) predictive model to identify the high-risk beneficiaries to be enrolled in the program. Medication therapy reviews were conducted for these patients. If any medication-related problems (MRPs) were identified, the patient's prescribers were contacted via a fax communication with recommendation(s) to resolve these MRPs. The UA MMC fax interventions were categorized as cost saving, guideline adherence, or safety concerns.
\end{abstract}

OBJECTIVES: To (a) determine prescriber responses to pharmacist-initiated recommendations in an MTMP for the 3 intervention categories, (b) compare prescriber responses between intervention categories, and (c) compare prescriber response by prescriber type (primary care physician [PCP] vs. specialist) within each intervention category.

METHODS: A retrospective analysis of pharmacist-initiated interventions from August through December 2008 was performed using data collected from the UA MMC database. Data were collected on intervention category (cost saving, guideline adherence, or safety concerns), and responses of prescribers were recorded as either approval or decline (no response was considered decline). Prescriber specialty was identified from searching records of state medical boards. Logistic regression analyses with the robust variance option to adjust for correlation within prescribers were conducted to compare prescriber approval rates between and within intervention categories. Significance was assessed at alpha 0.05 .

RESULTS: Of 4,967 Medicare Part D beneficiaries determined to be MTMPeligible, 4,277 beneficiaries ( $86.1 \%$ ) were available for assessment (400 declined, 186 disenrolled, and 104 were deceased). Pharmacists initiated 1,548 valid medication recommendations (i.e., recommendations were excluded for deceased patients, incorrect prescribers, and where prescriber specialty was not identified). These recommendations for 1,174 beneficiaries ( $27.5 \%$ of those available) were faxed to prescribers requesting approval. Mean (SD) age for beneficiaries having recommendations was 72.9 (9.4) years, and the majority (57.6\%) was female. By category of recommendation, $58.3 \%(n=902)$ were guideline adherence, $33.3 \%$ ( $n=515)$ were cost saving, and $8.5 \%(n=131)$ were safety concerns. Prescriber approval rates were $47.2 \%$ overall $(n=731 / 1,548), 41.4 \%$ ( $n=373 / 902)$ for guideline adherence, $58.3 \%(n=300 / 515)$ for cost savings, and $44.3 \%(n=58 / 131)$ for safety concerns; 817 recommendations were not approved by prescribers $(n=255$ [16.5\%] denials and 562 no response [36.3\%]). Prescriber approval was significantly higher for costsaving interventions compared with guideline adherence interventions (odds ratio $[\mathrm{OR}]=1.98,95 \% \mathrm{Cl}=1.56-2.51, P<0.001$ ) and compared with safety interventions $(\mathrm{OR}=1.76,95 \% \mathrm{Cl}=1.19,2.59, P=0.004)$; there was no significant difference in the prescriber approval rates for the interventions for safety versus guideline adherence. The overall approval rate was higher for PCPs $(49.8 \%, n=525 / 1,054)$ versus specialists $(41.7 \%$, $\mathrm{n}=206 / 494 ; 0 \mathrm{R}=1.39,95 \% \mathrm{Cl}=1.08-1.78, P=0.011)$ and for the category for guideline adherence interventions $(44.0 \%$ for PCPs vs. $35.9 \%$ for specialists; $\mathrm{OR}=1.40,95 \% \mathrm{Cl}=1.01-1.95, P=0.044)$, but not for the other 2 intervention categories.

CONCLUSIONS: Prescriber approval rates for pharmacist recommendations for drug therapy changes for MTMP beneficiaries were approximately $47 \%$ overall and higher for recommendations that involved cost savings compared with recommendations for safety concerns or guideline adherence. Compared with specialists, PCPs had higher approval rates for pharmacist recommendations overall and for the intervention category guideline adherence.

\section{J Manag Care Pharm. 2011;17(5):345-54}

Copyright $\odot$ 2011, Academy of Managed Care Pharmacy. All rights reserved.

\section{What is already known about this subject}

- Medication therapy management programs (MTMPs) have the potential to resolve and prevent medication-related problems (MRPs) that pose a tremendous economic burden in morbidity and mortality costs for individuals, health care systems, and society. These costs were estimated to exceed $\$ 177$ billion in 2000 .

- Successful implementation of MTMPs and resolution of MRPs require collaboration among prescribers, pharmacists, and patients. Prescriber approval of pharmacist-initiated recommendations in different settings has been shown to vary depending on the setting and method of intervention. Prescriber approval rates of more than $90 \%$ have been reported for face-to-face interactions and collaborative care agreements in clinic settings, whereas approval rates have been lower (32\% to 61\%) when recommendations are conveyed through written communications such as mail and fax. 


\section{What this study adds}

- An MTMP provided to approximately 5,000 high-risk Medicare beneficiaries yielded 1,548 pharmacist-initiated medication recommendations faxed to 1,163 prescibers for 1,174 patients in a 5-month period. Of the 3 categories of interventions, the majority of the medication recommendations were related to guideline adherence (58.3\%), followed by cost savings (33.3\%) and safety interventions (8.5\%).

- The overall prescriber approval rate for these recommendations was 47.2\%; 255 recommendations were denied (16.5\%); and 562 (36.3\%) had no response. Approval rates ranged from $41.4 \%$ for guideline adherence to $58.2 \%$ for cost-saving recommendations.

- Faxed medication recommendations containing an evidencebased rationale may be a viable method of communicating MRPs to prescribers. Prescriber approval of pharmacist-initiated recommendations can vary significantly by intervention category. Prescriber approval of cost-saving interventions was higher than the approval rates for interventions for safety concerns (odds ratio $[\mathrm{OR}]=1.76,95 \% \mathrm{CI}=1.19-2.59, \mathrm{P}=0.004$ ) or guideline interventions (OR=1.98, 95\% CI =1.56-2.51, $\mathrm{P}<0.001)$. Overall prescriber approval also varied with prescriber type; the approval rate for primary care physicians was significantly higher than for specialists $(\mathrm{OR}=1.39,95 \% \mathrm{CI}=1.08-1.78, \mathrm{P}=0.011)$.

$\mathrm{M}$ edication therapy management (MTM) encompasses a wide range of patient-centered services provided by pharmacists in a number of different care settings. ${ }^{1-4}$ MTM services, which involve a comprehensive evaluation of a patient's medication regimen in its entirety, are separate from but can occur in conjunction with dispensing and product-centered delivery of pharmacy services. ${ }^{1,2,4}$ Examples of MTM services or components include medication reviews, therapeutic drug monitoring, disease management, wellness programs, immunizations, and other programs designed to optimize medication treatment. ${ }^{4}$ MTM was mandated by the Medicare Prescription Drug, Improvement, and Modernization Act (MMA 2003). ${ }^{5}$ The law requires all Medicare Part D prescription drug plan (PDP) sponsors to establish an MTM program (MTMP) for targeted beneficiaries. The program must be designed to "optimize therapeutic outcomes" through the improvement of medication utilization and reduction in the risk of adverse events. ${ }^{5}$ Additionally, the MMA 2003 mandates that MTMPs shall be developed in cooperation with licensed pharmacists and physicians but may be offered by other qualified providers. ${ }^{6}$

Medication-related problems (MRPs) pose significant health risks to vulnerable populations within the United States and are a tremendous economic burden to individuals, the health care system, and society at-large. ${ }^{7,8}$ MRPs, as identified by Johnson and Bootman (1995), include untreated indications, improper drug selection, subtherapeutic dosage, drug use without indication, adverse drug reactions, drug interactions, and overdosage. ${ }^{8}$ In 2000, morbidity and mortality costs attributed to MRPs were estimated to be more than $\$ 177$ billion. ${ }^{7}$ Furthermore, the number of adverse drug events in the United States is estimated at 1.5 million annually. ${ }^{9}$ Given the extensive burden borne by individuals and systems, the promise of MTMPs to yield cost savings through the resolution and prevention of MRPs is substantial. ${ }^{4,10-14}$

Successful implementation of MTM requires the collaboration of patients and their health care providers. Studies and several reviews conducted on the subject have shown that physicians in general respond favorably to pharmacist interventions ${ }^{15-17}$ and acknowledge clinical pharmacists as playing a valuable role as medication therapy specialists to improve the clinical status of patients. ${ }^{15,18}$ Furthermore, systematic reviews and studies conducted across a number of disease conditions and pharmaceutical care delivery settings have, in most instances, suggested improved patient outcomes following an active role by the pharmacist. ${ }^{19-22}$ However, perceptions of physician resistance as a barrier in providing services can differ among MTM providers and payers. ${ }^{23,24}$ In a nationwide survey by Schommer et al. (2008), barriers to MTM services were assessed for both pharmacists who provide MTM services and payers of the service. ${ }^{23,24}$ Pharmacists who provided MTM services did not indicate physician resistance as an important barrier; only $23 \%$ of pharmacists reported local physician resistance as a very important or somewhat important barrier to service provision (ranked 14th of 15 barriers assessed). ${ }^{23}$ However, the second most frequently reported barrier by payers of MTMPs was physician resistance or suboptimal cooperation. ${ }^{24}$ This resistance is important given that cooperation from physicians is essential for successful MTM.

Although not always described as MTM, pharmacists' recommendations targeted at resolving potential MPRs have been the subject of numerous studies in various settings and countries. ${ }^{15,18,25-33}$ Reported physician acceptance rates among these studies varied between 32\% and 98\%. ${ }^{15,18,25-33}$ Higher acceptance rates were observed in the presence of face-to-face interaction or collaborative agreements between pharmacists and physicians. ${ }^{15,18,28,32}$ Rates of acceptance of recommendations consisting of less personal contact, such as letters and faxes, were lower. ${ }^{25-27}$ Pharmacist-initiated recommendations in these studies broadly consisted of achieving optimal treatment for patients (e.g., stoppage of unnecessary/ineffective medications, dosage adjustments, medication adherence, medication switches, and addition of new medications) and addressing safety concerns such as potential adverse events due to drug interactions or inappropriate drug use in the elderly.

The University of Arizona (UA) College of Pharmacy, through its Medication Management Center (MMC) provides MTM services to Medicare Part D beneficiaries from several 
Evaluation of Prescriber Responses to Pharmacist Recommendations

Communicated by Fax in a Medication Therapy Management Program (MTMP)

\section{TABLE 1 Frequently Occurring Pharmacist-Initiated Prescription Fax Interventions by Intervention Category}

\begin{tabular}{|c|c|c|}
\hline Intervention Category & Reason for Intervention & Common Examples \\
\hline \multicolumn{3}{|c|}{ Cost Saving Interventions } \\
\hline Drug substitution & $\begin{array}{l}\text { Patient is on higher-tier (higher-cost) } \\
\text { formulary medication when a lower-tier } \\
\text { (lower-cost) medication alternative is } \\
\text { appropriate for substitution. }\end{array}$ & $\begin{array}{l}\text { - Generic substitution of brand (innovator) statin (e.g., replace rosuvastatin with sim- } \\
\text { vastatin) } \\
\text { - Generic substitution of brand (innovator) PPI (e.g., replace esomeprazole with generic } \\
\text { omeprazole) }\end{array}$ \\
\hline \multicolumn{3}{|c|}{ Guideline Adherence Interventions } \\
\hline Untreated indication & $\begin{array}{l}\text { Patient is not on medication } \\
\text { recommended by clinical practice } \\
\text { guidelines based on evidence of benefit. } \\
\text { Interventions were targeted for } \\
\text { patients with diabetes, heart failure, } \\
\text { post-myocardial infarction, chronic } \\
\text { kidney disease, COPD, asthma, and } \\
\text { angina. }\end{array}$ & $\begin{array}{l}\text { - ACE inhibitor or an ARB is recommended to reduce the risk of adverse renal and/or } \\
\text { cardiovascular outcomes in patients with diabetes and specific comorbidities (hyper- } \\
\text { tension, known cardiovascular disease, or any degree of proteinuria). } \\
\text { - Statin is recommended to reduce risk of adverse cardiovascular outcomes in patients } \\
\text { with diabetes and specific comorbidities (known cardiovascular disease or age greater } \\
\text { than } 40 \text { years and certain risk factors). } \\
\text { - ACE inhibitor or ARB and a beta-blocker are recommended with the goal of improv- } \\
\text { ing survival in patients with heart failure. } \\
\text { - ACE inhibitor and statin are recommended for secondary prevention in patients fol- } \\
\text { lowing an MI. } \\
\text { - Short-acting beta2-agonists are recommended as first-line therapy for acute symptoms } \\
\text { and exacerbations in patients with asthma and COPD. } \\
\text { - Inhaled corticosteroids are recommended to manage asthma in patients experiencing } \\
\text { symptoms more than twice weekly. }\end{array}$ \\
\hline \multicolumn{3}{|l|}{ Safety Interventions } \\
\hline $\begin{array}{l}\text { Drug-disease } \\
\text { interactions }\end{array}$ & $\begin{array}{l}\text { Patient is on medication that may } \\
\text { worsen co-existing conditions. }\end{array}$ & $\begin{array}{l}\text { - Recommend switch of nonselective beta-blockers to a cardio-selective beta-blocker in } \\
\text { patients with asthma and COPD } \\
\text { - Discontinue anticholinergic medications in elderly patients } \\
\text { - Discontinue or adjust dosages of nephrotoxic drugs in patients with renal dysfunction } \\
\text { - Assess alternative therapy to calcium channel blockers in patients with heart failure }\end{array}$ \\
\hline Avoidance of ADEs & $\begin{array}{l}\text { Adjustment of patient's medication } \\
\text { dosage or regimen is needed to prevent } \\
\text { future or current side effects or } \\
\text { complications. }\end{array}$ & $\begin{array}{l}\text { - Adjust dosage when medication dose is too high (e.g., reduce dose of acetaminophen } \\
\text { when daily dose exceeds } 4,000 \text { mg due to risk of liver damage) } \\
\text { - Discontinue duplicate therapy while maximizing the dose of the other agent } \\
\text { - Assess addition of PPI in patients using chronic NSAIDS with risk factors, includ- } \\
\text { ing age older than } 65 \text { years or concomitant use of corticosteroids, anticoagulants, or } \\
\text { aspirin }\end{array}$ \\
\hline
\end{tabular}

$A C E=$ angiotensin-converting enzyme; $A D E=$ adverse drug event; $A R B=$ angiotensin II receptor blocker; $C O P D=$ chronic obstructive pulmonary disease; $m g=$ milligrams; $M I=$ myocardial infarction; NSAID = nonsteroidal anti-inflammatory drug; PPI = proton pump inhibitor; statin = HMG-CoA reductase inhibitor .

national and regional PDPs. A comprehensive description of the MTMP has been reported previously. ${ }^{34}$ In brief, UA MMC pharmacists regularly conduct comprehensive reviews of patients' medication profiles and make recommendations on identified MRPs via evidence-based faxes to the patient's prescriber. Faxes are of 2 types-prescription (recommendation) faxes and informational (FYI) faxes. MRPs are communicated through prescription faxes when there is adequate information to make a specific medication-related recommendation (i.e., a change in the patient's prescription). For prescription fax interventions, the UA MMC requests a fax response from the prescriber approving or declining the recommendation. FYI faxes are sent to the prescriber in the absence of complete information to make a prescription recommendation, but a potential MRP is identified in the patients' medication profile. FYI faxes do not require a signed response from the prescriber.
This study focuses on prescription fax recommendations that requested prescriber response. Recommendations made at the UA MMC are grouped into 3 broad intervention categories pre-determined by the pharmacist: (a) cost savings, (b) safety concerns, and (c) adherence to pharmacotherapeutic recommendations in national clinical practice guidelines (CPGs). Table 1 presents the most commonly occurring interventions in these 3 categories.

Prior to the present study, prescriber response to the 3 intervention categories within the MTMP at the UA MMC was unknown. Thus, the primary aim of this study was to assess prescriber responses to an MTM service model that utilized faxes as the primary method of communicating medication recommendations to prescribers. The specific objectives of the study were to (a) determine prescriber approval rates for pharmacist-initiated recommendations overall and by intervention 
category (cost saving, guideline adherence, safety concerns), (b) compare prescriber responses between intervention categories, and (c) compare prescriber approval rates by prescriber type (primary care physician [PCP] versus specialist) overall and within each intervention category.

\section{Methods}

This study was a retrospective review of faxed prescriber responses to pharmacist-initiated prescription fax recommendations. This review included 1,548 prescription recommendations for 1,174 patients, $27.4 \%$ of the 4,277 patients who were enrolled to receive MTM services in a pilot MTMP developed in collaboration with, and for WellPoint Inc., from August to December 2008. The present study was conducted after receipt of approval from the UA Institutional Review Board.

\section{Pilot Program and Study Setting}

The pilot program was conducted for 4,967 Medicare Part D beneficiaries identified by WellPoint Inc. as eligible to receive MTMP services. Target enrollment in the pilot program was limited to approximately 5,000 beneficiaries as this was deemed appropriate by WellPoint Inc. to sufficiently develop and implement an MTMP pilot program in collaboration with the UA MMC. From nearly 2 million Medicare beneficiaries in WellPoint Inc.'s affiliated PDPs, beneficiaries were selected for this MTMP pilot if they had been diagnosed with at least 2 of 6 chronic conditions (dyslipidemia, cardiovascular disease, depression, diabetes mellitus, congestive heart failure, and chronic obstructive pulmonary disease; at least 1 of the latter 2 diseases must be present), received 3 or more Part D-covered medications, and had greater than $\$ 4,000$ per year in predicted drug spending. In addition to these criteria, WellPoint Inc. used the Johns Hopkins adjusted clinical groups (ACG) predictive model ${ }^{35}$ to select the 4,967 high-risk beneficiaries for the MTMP pilot.

Enrollment for the pilot program was via an "opt-out" mechanism whereby all targeted beneficiaries were enrolled with the exception of disenrollment at beneficiary request that occurred when patients were contacted by telephone to perform medication reviews. Opportunities for interventions were evaluated by conducting reviews of medication profiles for 4,277 beneficiaries based on the 3 categories of cost savings, adherence to guidelines, and safety concerns, while 690 opted out of or were unavailable for the program (400 declined, 186 disenrolled, and 104 were deceased; Figure 1). Medication reviews were conducted via a telephone consultation with the patient, and if patients could not be contacted, a data (medication) review was conducted. Following these medication reviews, prescribers of 1,194 beneficiaries received 1,583 prescription fax recommendations from the UA MMC pharmacist. Prescription faxes included a short paragraph describing the rationale behind the intervention (e.g., reference to evidence-based national clinical practice guideline recommendations) followed by a

\section{FIGURE 1) Sample Selection Flowchart}

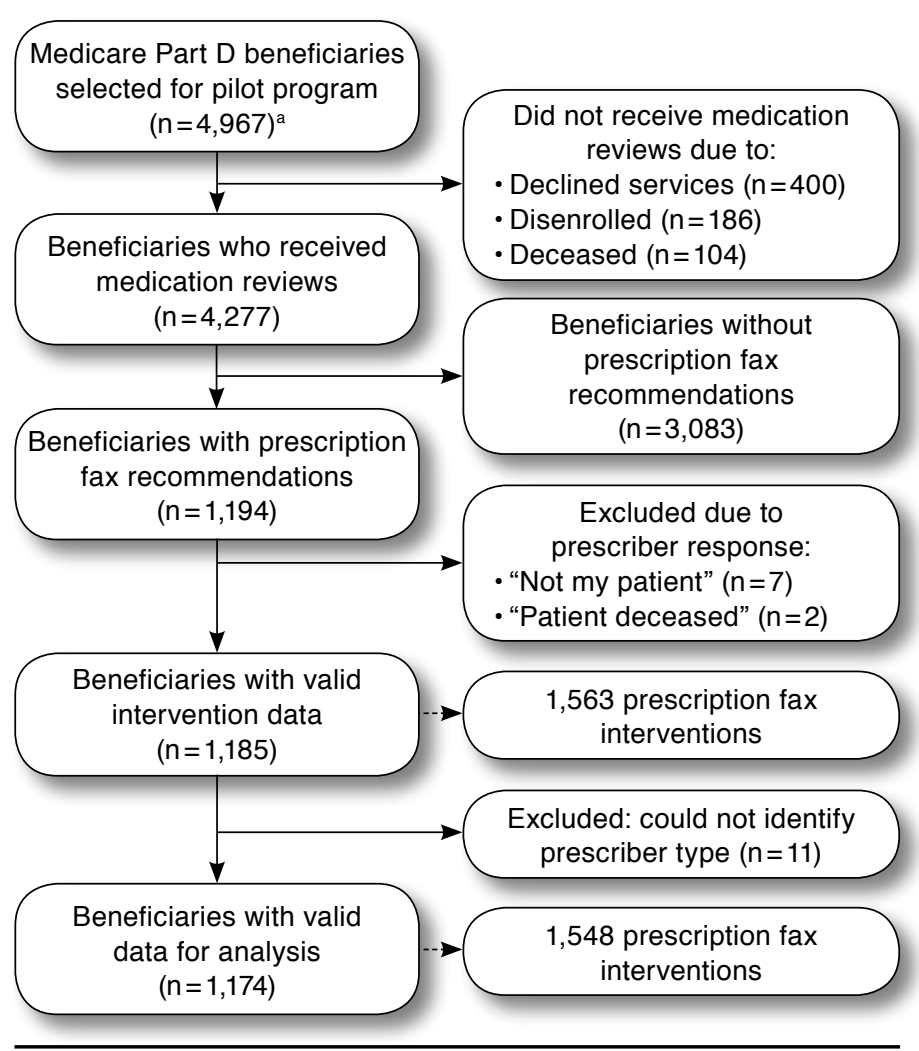

aThe health plan composed of approximately 2 million Medicare Part D beneficiaries referred 4,967 beneficiaries eligible for MTMP services.

MTMP = medication therapy management program.

recommended prescription. A fax response with an approval or decline of the recommendation was requested to be sent by the prescriber to the UA MMC. The remaining 3,083 beneficiaries without a prescription fax recommendation included patients whose prescribers received an FYI fax only (1,165 FYI faxes were generated during this study period), patients who did not consent to sending faxes to their prescriber, and patients without a MRP during the study period.

\section{Data Collection}

All pharmacist-initiated prescription recommendations requesting a fax response from the prescriber were included in this study. Faxes from prescribers stating "not my patient" (13 interventions in 7 patients) or "patient deceased" (7 interventions in 2 patients) were excluded from the analysis. This procedure identified a total of 1,563 interventions for 1,185 beneficiaries that were obtained from records maintained by the UA MMC. Records included a unique patient identification number, intervention category (cost savings, guideline adherence, or safety concern), target medications, and 
Evaluation of Prescriber Responses to Pharmacist Recommendations

Communicated by Fax in a Medication Therapy Management Program (MTMP)

TABLE 2 MTM Patient Characteristics ${ }^{a}$

\begin{tabular}{|c|c|c|c|c|c|c|c|c|c|}
\hline \multirow{2}{*}{$\begin{array}{l}\text { Patient Characteristics } \\
\text { Patient age (years) - mean [SD] }\end{array}$} & \multicolumn{2}{|c|}{$\begin{array}{c}\text { Overall } \\
\mathrm{n}=1,174 \\
\mathrm{n}(\%)\end{array}$} & \multicolumn{2}{|c|}{$\begin{array}{c}\text { PCP }+ \text { Specialist } \mathrm{S}^{\mathrm{b}} \\
\mathbf{n}=25 \\
\mathbf{n}(\%)\end{array}$} & \multicolumn{2}{|c|}{$\begin{array}{l}\text { PCP Only } \\
\text { n }=786 \\
\text { n (\%) }\end{array}$} & \multicolumn{2}{|c|}{$\begin{array}{c}\text { Specialist Only } \\
\mathrm{n}=363 \\
\mathrm{n}(\%)\end{array}$} & \multirow{2}{*}{$\frac{P \text { Value }^{\mathrm{c}}}{0.834}$} \\
\hline & 72. & {$[9.4]$} & 74. & {$[7.8]$} & 72. & {$[9.4]$} & & [9.4] & \\
\hline Female sex & 676 & $(57.6)$ & 13 & $(52.0)$ & 463 & $(58.9)$ & 201 & $(55.4)$ & 0.26 \\
\hline \multicolumn{10}{|l|}{ Comorbidities $^{\mathrm{d}}$} \\
\hline Cardiovascular diseases & 1,148 & $(97.9)$ & 24 & $(96.0)$ & 770 & $(98.1)$ & 354 & $(97.5)$ & 0.531 \\
\hline Diabetes mellitus & 770 & $(65.6)$ & 17 & $(68.0)$ & 528 & $(67.2)$ & 225 & $(62.0)$ & 0.085 \\
\hline Respiratory (COPD or asthma) & 624 & $(53.1)$ & 12 & $(48.0)$ & 433 & $(55.1)$ & 179 & $(49.3)$ & 0.068 \\
\hline Gastroesophageal reflux disease & 599 & $(51.0)$ & 15 & $(60.3)$ & 402 & $(51.2)$ & 182 & $(50.1)$ & 0.751 \\
\hline Chronic pain & 572 & $(48.7)$ & 9 & $(36.0)$ & 399 & $(50.8)$ & 164 & $(45.2)$ & 0.078 \\
\hline Depression/dementia & 466 & $(39.7)$ & 9 & $(36.0)$ & 326 & $(41.5)$ & 131 & $(36.1)$ & 0.083 \\
\hline Osteoporosis & 110 & $(9.4)$ & 3 & $(12.0)$ & 77 & $(9.8)$ & 30 & $(8.3)$ & 0.406 \\
\hline Chronic kidney disease & 89 & $(7.6)$ & 3 & $(12.0)$ & 33 & $(4.2)$ & 53 & $(14.6)$ & $<0.001$ \\
\hline \multicolumn{10}{|c|}{$\begin{array}{l}\text { aThe MTM interventions with prescribers were made from August through December } 2008 . \\
\text { bPatients with prescriptions from both PCP and specialist. } \\
\text { cP values for comparison of PCP only versus specialist only; P values calculated with independent t-tests and Pearson chi-square. } \\
{ }^{d} \text { Comorbidities were inferred from medications. } \\
C O P D=\text { chronic obstructive pulmonary disease; } P C P=\text { primary care physician; } S D=\text { standard deviation. }\end{array}$} \\
\hline
\end{tabular}

prescriber response. Patient identification numbers were used to access the patient's medication profile in the UA MMC database to verify the prescriber response for each recommendation. Additional demographic data such as age and sex were extracted from the patient medication profile. Comorbid conditions were inferred from drug therapy.

Three possible prescriber responses were identified in the UA MMC database: (a) signed and returned fax accepting the recommendation (i.e., approval), (b) signed and returned fax declining the recommendation, and (c) no returned fax (i.e., no response). For the purpose of this study, prescriber response was dichotomized as an approval or decline with the latter including both returned fax declines and no responses to the pharmacist recommendations.

For the analysis by prescriber type, prescribers were classified as either PCPs or specialists. The classification scheme was determined by first identifying the prescribers and their states of practice from the MMC database. Next, state medical board websites were accessed to determine the medical specialty for each individual physician. Physicians were from 30 different states, and the websites used to determine prescriber medical specialty included ABMS (American Board of Medical Specialties) and state medical boards (e.g., www.medbd.ca.gov for the Medical Board of California and www.med.ohio.gov for the State Medical Board of Ohio). Family medicine and/ or internal medicine physicians without any documented specialty certifications were defined and grouped as PCPs. Family medicine and/or internal medicine physicians who also had a specialty certification were defined and categorized as specialists. All other practitioners were also categorized as specialists, which included but were not limited to cardiology, endocrinology, geriatrics, gastroenterology, nephrology, pulmonology, nursing (i.e., advance practice nurse prescriber, nurse anesthetist, nurse practitioner), and other categories. A de-indentified database was constructed containing the aforementioned data elements. Due to incomplete information in the MMC database, prescriber type was not ascertained for 15 interventions; thus, these were excluded from the prescriber type analysis.

\section{Analytic Strategy}

Descriptive statistics were generated for all variables. Means (SD) were reported for continuous variables (patient age), while frequencies and percentages were reported for categorical variables (i.e., patient sex, comorbidities, intervention category, prescriber approval). Patient characteristics were presented for the overall sample as well as by prescriber type (i.e., patients with faxes sent to PCPs only, specialists only, and for both PCPs and specialists). Independent t-tests and Pearson chisquare were conducted to determine if patient characteristics deferred between patients with faxes sent to PCPs only and patients with faxes sent to specialists only. Logistic regression analyses with the robust variance option to adjust for correlation within prescribers were conducted to compare prescriber approval of pharmacist recommendations between intervention categories for the overall sample and by prescriber type (PCP and specialist) and to compare prescriber approval by prescriber type (PCP versus specialist) for each intervention category. Results are presented as odds ratios (OR), 95\% confidence intervals (CI) along with their $P$ values. Significance was assessed at 0.05. Data were analyzed using Stata statistical software version 10.1 (StataCorp, College Station, TX). 
Evaluation of Prescriber Responses to Pharmacist Recommendations

Communicated by Fax in a Medication Therapy Management Program (MTMP)

TABLE 3 MTM Recommendation Approval Rates by Prescriber Type and Intervention Category

Comparison by $\quad$ Comparison Prescriber Type Odds by Prescriber

\begin{tabular}{l|l|r} 
Overall & PCPs & Specialists \\
\hline
\end{tabular}

Ratio (95\% Confidence Type

Overall

\begin{tabular}{|c|c|c|c|c|c|c|c|c|c|}
\hline Cost savings & 58.2 & $(300 / 515)$ & 60.8 & $(225 / 370)$ & 51.7 & $(75 / 145)$ & 1.45 & $(0.95-2.20)$ & 0.082 \\
\hline Safety & 44.3 & $(58 / 131)$ & 42.5 & $(34 / 80)$ & 47.1 & $(24 / 51)$ & 0.83 & $(0.41-1.68)$ & 0.608 \\
\hline Guideline adherence & 41.4 & $(373 / 902)$ & 44.0 & $(266 / 604)$ & 35.9 & $(107 / 298)$ & 1.40 & (1.01-1.95) & 0.044 \\
\hline Total for all types & 47.2 & $(731 / 1,548)^{c}$ & 49.8 & $(525 / 1,054)$ & 41.7 & $(206 / 494)$ & 1.39 & $(1.08-1.78)$ & 0.011 \\
\hline
\end{tabular}

\begin{tabular}{l|cc|cc|r}
\hline Total for all types & 47.2 & $(731 / 1,548)^{\mathrm{c}}$ & 49.8 & $(525 / 1,054)$ & 41.7 \\
\hline Odds ratios (95\% confidence intervals) for comparisons between intervention categories & $\mathbf{d}$
\end{tabular}

\begin{tabular}{l|ll|ll|ll|l|l}
\hline Savings versus safety & 1.76 & $(1.19-2.59)$ & 2.10 & $(1.29-3.41)$ & 1.21 & $(0.63-2.30)$ & NA & NA \\
\hline Savings versus guideline adherence & 1.98 & $(1.56-2.51)$ & 1.97 & $(1.48-2.62)$ & 1.91 & $(1.24-2.94)$ & NA & NA \\
\hline Safety versus guideline adherence & 1.13 & $(0.78-1.63)$ & 0.94 & $(0.59-1.49)$ & 1.59 & $(0.86-2.92)$ & NA & NA \\
\hline
\end{tabular}

$P$ values for comparisons by intervention category ${ }^{\mathrm{e}}$

\begin{tabular}{l|c|c|c|c}
\hline Savings versus safety & 0.004 & 0.003 & 0.571 & NA \\
\hline Savings versus guideline adherence & $<0.001$ & $<0.001$ & 0.003 & NA \\
\hline Safety versus guideline adherence & 0.525 & 0.791 & 0.138 & NA \\
\hline
\end{tabular}

${ }^{a}$ Odds ratios and 95\% confidence intervals from logistic regression analyses comparing approval rates for PCPs versus specialty prescriber. The analyses took into account the correlation that may be present among physicians that received more than 1 fax recommendation.

${ }^{b} P$ values from logistic regression analyses testing approval rates for PCPs versus specialist prescribers.

cThere were 255 prescriber denials (16.5\%) and 562 (36.3\%) no responses of the 817 recommendations not approved by prescribers.

${ }^{d}$ Odds ratios and $95 \%$ confidence intervals from logistic regression analyses testing prescriber approval rates between intervention categories. The analyses took into

account the correlation that may be present among physicians that received more than 1 fax recommendation.

eP values from logistic regression analyses testing prescriber approval rates between intervention categories.

$M T M=$ medication therapy management; $P C P=$ primary care provider

\section{Results}

During the 5 months of the 2008 pilot MTMP, UA MMC pharmacists initiated a total of 1,563 interventions that included a prescription recommendation for approval for 1,185 beneficiaries (27.7\% of the 4,277 enrollees). Excluding the 15 interventions where prescriber information could not be found for prescriber categorization (PCP or specialist), a total of 1,548 interventions were sent to 1,164 unique prescribers for 1,174 beneficiaries. This was considered the final sample, and all analyses were conducted and reported for this sample. Of the 1,163 prescribers, 776 (66.7\%) were PCPs, and 387 (33.3\%) were specialists. Patient characteristics and comorbidities are presented in Table 2. Beneficiaries who were the subjects of the interventions were aged a mean (SD) 72.9 (9.4) years, and more than one-half $(57.6 \%)$ were female. The most frequently occurring comorbidities were cardiovascular diseases (97.9\%), diabetes mellitus (65.7\%), and respiratory diseases (53.1\%). It is expected that cardiovascular disease and respiratory disease occur frequently in this patient population because patients were required to have either congestive heart failure or chronic obstructive pulmonary disease to be included in the pilot program. With the exception of chronic kidney disease, there were no significant differences for patient age, gender, or other chronic conditions between patients with faxes sent to PCPs only versus specialists only.

\section{Prescriber Approval of Intervention Categories}

Table 3 presents the number of pharmacist-initiated prescription fax recommendations and prescriber approval of these recommendations by intervention category. Of the total of 1,548 recommendations, the largest intervention category was guideline adherence at $58.3 \%(n=902)$, while the lowest was safety concerns with less than $8.5 \%(n=131)$. Cost savings accounted for one-third of the total $(n=515)$. Across all intervention categories, overall prescriber approval of pharmacist recommendations was $47.2 \%(n=731)$. Prescriber denials were $16.5 \%$ $(n=255)$, and no responses were $36.3 \%(n=562)$. Approval was highest for cost saving interventions at 58.3\% $(n=300)$ and lowest for guideline adherence at $41.4 \%(n=373)$. Even among PCPs and specialists, approval was highest among cost saving interventions (60.8\% and 51.7\%, respectively). Approval was lowest for safety interventions among PCPs (42.5\%) and for guideline adherence interventions among specialists (35.9\%).

\section{Comparison of Prescriber Approval Rates Between Intervention Category}

Table 3 presents the results of the comparisons of prescriber approval between intervention categories. Prescriber approval of cost saving interventions was significantly greater than both guideline adherence ( $\mathrm{OR}=1.98,95 \% \mathrm{CI}=1.56-2.519$, $P<0.001)$ and safety interventions $(\mathrm{OR}=1.76,95 \% \mathrm{CI}=1.19$ $2.59, P=0.004)$. There was no significant difference between 
prescriber approval of guideline adherence and safety interventions $(\mathrm{OR}=1.13,95 \% \mathrm{CI}=0.78-1.63 ; \mathrm{P}=0.470)$. These relationships remained following the subgroup analyses by PCPs and specialists with 1 exception-among specialists there was no significant differences in approval between cost savings and safety interventions $(\mathrm{OR}=1.21,95 \% \mathrm{CI}=0.63-2.30, \mathrm{P}=0.571)$.

\section{Approval of Interventions by Prescriber Type}

Table 3 presents the results of approval by PCPs and specialists for the overall sample and for each intervention category. Overall approval of all pharmacist recommendations by PCPs was significantly greater compared with approval by specialists $(\mathrm{OR}=1.39,95 \% \mathrm{CI}=1.08=1.78, \mathrm{P}=0.011)$. When approval by each intervention category was considered, significant differences in approval by prescriber type was only observed for guideline adherence interventions. Approval among PCPs were greater compared with approvals among specialists $(\mathrm{OR}=1.40$, $95 \% \mathrm{CI}=1.01-1.95, P=0.044)$. It may be possible that these results are driven by the different patient populations that are treated by PCPs versus specialists, with specialists likely to be treating a sicker group of patients. From the available patient characteristics only, chronic kidney disease showed significant differences between prescriber type. Specialists only had a greater number of patients with chronic kidney disease compared with PCPs only $(14.6 \%$ vs. $4.2 \%, P<0.001)$. A sensitivity analysis was conducted for the overall sample among subgroups of patients with and without chronic kidney disease to explore if this is accounting for the significant differences in approval that were observed between prescriber type. No significant differences between PCPs versus specialists were found in this subgroup analysis. [data not shown]

\section{Discussion}

This study presented the results of an analysis of prescriber approvals within an opt-out pilot MTMP providing services to Medicare Part D PDP beneficiaries. Recommendations were delivered via fax to prescribers, and approval rates ranged from $41.4 \%$ for guideline adherence recommendations to $58.2 \%$ for cost saving recommendations, with an overall approval rate of $47.2 \%$ across intervention categories. These values were within the range of physician acceptance of pharmacist-initiated recommendations (32\% to $98 \%$ ) reported in numerous other studies, albeit in differing settings, ${ }^{15,18,25-33}$ suggesting that prescribers are receptive to UA MMC's MTM model in which recommendations are initiated and communicated via faxed prescription requests. In several studies that communicated recommendations via fax, physician acceptance ranged between $32 \%$ and $49.2 \% .^{26,27,29}$ Overall approval in the current study falls within the upper end of this range. Physician acceptance rates of greater than $90 \%$ of pharmacist recommendations reported in several studies are substantially higher than those in the present study and are likely attributable to collaborative agreements and/or face-to-face interaction between the pharmacist and the physician in family medicine or primary care clinic settings. ${ }^{15,18,28,32}$

A prescriber approval rate comparable to the rates in the present study was reported in an MTM service provision model similar to that of the UA MMC. ${ }^{26}$ In the study of an MTMP implemented by Iowa Medicaid reported by Doucette et al. (2005), physicians and community pharmacists were compensated for collaborating in the provision of MTM services to high-risk patients. ${ }^{26}$ Similar to the UA MMC's MTMP, the community pharmacist performed an initial review of the patient's medications and medical history and faxed all recommendations to the patient's physician, who then faxed back an approval or decline. Of the total 659 pharmacist-initiated interventions, 313 were accepted by the physician, resulting in an approval of $47.5 \%$ of all recommendations. ${ }^{26}$

In the present study, interventions for guideline adherence constituted the largest number of pharmacist-initiated prescription recommendations (902 of 1,548 recommendations, $58.3 \%)$, followed by cost saving $(n=515,33.2 \%)$ and safety interventions ( $n=131,8.5 \%$ ). In support of this finding, a number of studies that evaluated MRPs reported "untreated indication" or the need to add a new medication to manage medical condition (in line with CPG recommendations) to be among the most frequently occurring MRPs. ${ }^{11,26,28,29,36}$

Comparison of prescriber approval by intervention category across studies is challenging due to the number of ways in which existing research has reported the categorization of pharmacist interventions. For guideline interventions, the study by Doucette et al. reported a physician acceptance rate of $41.7 \%$ for addition of new medication, which had the lowest approval rate among a number of recommendations. This finding is similar to that in the current study of a $41.41 \%$ prescriber approval rate for guideline adherence recommendations. ${ }^{26}$ In terms of cost-saving interventions, 1 study reported physician approval of formulary recommendations (i.e., generic substitution, conversion of nonformulary drug to formulary drug). ${ }^{25}$ This study by DeName et al. (2008) assessed MTM services provided via a free-standing ambulatory clinic and recommendations communicated to physicians through postal or intercampus mail. ${ }^{25}$ The approval rate for formulary recommendations was $67.5 \%$, compared with $58.2 \%$ approval rate for cost-saving interventions in the current study. ${ }^{25}$ The higher approval rate in the study by DeName et al. may be due to the collaborative care agreements between physicians and pharmacists that were in place within the ambulatory clinic. ${ }^{25}$ Comparisons of prescriber approval of safety interventions between the present study and existing literature are more difficult for the 3 intervention categories because of reported rates of physician approval for individual safety recommendations or the incorporation of safety recommendations within a broader category of medication-related interventions. 
Although several studies have reported physician approval of recommendations for different categories of interventions, ${ }^{25,26}$ the current study additionally evaluated if prescriber approval rates varied between intervention categories. In the current study, approval of cost saving interventions (58.2\%) was significantly higher than approval for both guideline adherence (41.0\%) and safety concern recommendations (44.3\%), but prescriber approval rates for guideline adherence and safety concern recommendations did not significantly differ. One possible reason for higher approval of cost-savings interventions may be the ease of prescriber decision making for these recommendations, which often involved a switch from brand name drug to the generic equivalent and may be perceived by prescribers as "low risk." Unlike brand to generic medication changes, guideline adherence and safety concern interventions frequently involved a notable change in medication therapy (e.g., addition of an angiotensin-converting enzyme inhibitor to the regimen of a diabetic patient). In a review of studies assessing prescriber response to drug safety alerts in computerized physician order entry, safety alerts were overridden by physicians in $49 \%$ to $96 \%$ of cases,${ }^{37}$ suggesting that it is not uncommon to have low prescriber approval rates for safety recommendations.

The reasons for lower prescriber approval rates for guideline adherence can be numerous and should be considered for future research. As previously discussed, untreated indications are one of the most common MRPs, and a number of studies have shown that a considerable proportion of patients with certain indications do not receive appropriate pharmacotherapy established in CPGs. ${ }^{38-41}$ Addition of a new drug to a patient's medication profile can be viewed as different from a cost-saving or safety concern intervention because it may require additional patient information or consume more of the prescriber's time, perhaps causing the prescriber to set aside the fax recommendation. Excluding prescriber nonresponse in our study, the combined rate for returned faxes with either an approval or denial was lowest for guideline adherence (59.0\%) versus $68.7 \%$ for cost saving and $76.3 \%$ for safety concerns (data not reported in tables). Prescriber responses to clinical recommendations can involve the complex phenomenon of psychological reactance including implied threat, particularly for unsolicited recommendations. ${ }^{42}$

The present study also found that overall approval of all recommendations and approval rates for guideline adherence recommendations were lower for specialty prescribers than for PCPs. However, differences were not observed for the other intervention categories. This finding may be attributed to a myriad of factors including specialist training, focus on a single morbidity of the patient, the lack of awareness of medications prescribed by other prescribers (e.g., a pain specialist may be prescribing a pain medication while paying less attention to a patient's other diseases). On the other hand, PCPs in general may have more information regarding the patient's total drug regimen along with greater responsibility to manage all of a patient's conditions and, as such, may have a greater willingness to approve pharmacist recommendations. From the available information, assessment of baseline characteristics and sensitivity analysis did not indicate that the difference in rate of prescriber approval of pharmacist recommendations for specialists versus PCPs was attributable to treating clinically different patient populations. The findings in the present study suggest the potential need to approach the specialist differently than the PCP when initiating a medication-related recommendation.

\section{Limitations}

Although the results of this study are informative and represent a real-world intervention, there are several limitations. First, failure to receive a fax from the prescriber (i.e., no response) was conservatively defined as a prescriber decline in the present study. It is possible that the prescriber may have addressed the recommendation without informing the MMC. This information was unavailable, and if this occurred, prescriber approval could be higher than that reported. Lack of a response could be attributed to several reasons including but not limited to nonacceptance of MTM services by the prescriber, disagreement with recommendation, forgetting to respond, the decision to postpone action on the recommendation until the next consultation with the patient, following through on the recommendation without informing the MMC, recommendations not clinically appropriate, or incorrect fax number. Second, we were primarily interested in prescriber approval rates by category of intervention and therefore did not examine the reasons for prescriber denials and no response. The reasons for prescriber nonresponse and denials have potential implications for process quality improvement and should be explored in future studies.

Third, because prescriber categories were based on board certifications available on websites, these may not reflect complete accuracy of prescriber practice and thus could affect the reported findings by prescriber type. Furthermore, we incorporated the nurse category under specialty prescribers (39 interventions from 29 nurse prescribers); some nurses may work in primary care practices and would therefore be misclassified. Fourth assessment of baseline characteristics and sensitivity analysis from available information did not indicate that the difference in approval rates observed between PCPs and specialists were likely due to prescribers treating clinically different patient populations. However, it is possible that the available information may not be adequate to establish definitively that the patient populations were similar.

Fifth, it is possible that prescribers who are younger and who have fewer years in practice are more responsive to pharmacist recommendations than prescribers who are older and have 
practiced for a longer period of time. Since such information on prescriber characteristics was not available, they were not controlled for in the analysis. Sixth, these study results pertain only to interventions for approximately $25 \%$ of the high-risk beneficiaries enrolled in the pilot MTMP. Finally, because of the method of referral of the 4,967 patients to this pilot MTMP from a population of approximately 2 million Medicare Part D beneficiaries, this sample may not be representative of MTMPeligible beneficiaries in Medicare PDPs.

\section{Conclusions}

Although lower than the prescriber approval rates of pharmacist recommendations reported previously for face-to-face interactions, prescribers overall responded favorably to an MTMP that communicated recommendations via prescription faxes. The differences in the rates of prescriber approval by category of pharmacist-initiated recommendations, as well as differences in approval by prescriber type, suggest an opportunity for future research, particularly in examination of the reasons for prescriber denial and nonresponse. Future research focusing on optimal communication and educational methods targeting observed differences may be useful to better understand how to increase prescriber response and approval of pharmacist-initiated recommendations.

\section{Authors}

PRASADINI N. PERERA, MS, is Graduate Research Assistant, College of Pharmacy; MIGNONNE C. GUY, PhD, is Assistant Research Scientist, Center for Health Outcomes and PharmacoEconomic Research; ASHLEY M. SWEANEY, PharmD candidate, is a Pharmacy Intern, Medication Management Center; and KEVIN P. BOESEN, PharmD, is Director, Medication Management Center, University of Arizona, Tucson, Arizona.

AUTHOR CORRESPONDENCE: Mignonne C. Guy, PhD, Center for Health Outcomes and PharmacoEconomic Research, University of Arizona, 1295 N. Martin Ave., Tucson, AZ 85721-0202. Tel: 520.626.6478; E-mail: guy@pharmacy.arizona.edu.

\section{DISCLOSURES}

This work was supported in part by Wellpoint Inc. through a service contract with the Arizona Board of Regents at the University of Arizona's College of Pharmacy Medication Management Center. The authors report no financial or other conflicts of interest.

Guy conceived and designed this study, Sweaney collected the data, and Perera interpreted the data. Perera wrote the manuscript with the assistance of Guy and Sweaney, and Guy revised the manuscript with the assistance of Boesen and Perera.

\section{REFERENCES}

1. American Pharmacists Association; National Association of Chain Drug Stores Foundation. Medication therapy management in pharmacy practice: core elements of an MTM service model (version 2.0). J Am Pharm Assoc (2003). 2008;48(3):341-53. Available at: http://www.accp.com/docs/positions/misc/CoreElements.pdf. Accessed May 30, 2011.

2. Bluml BM. Definition of medication therapy management: development of professionwide consensus. J Am Pharm Assoc (2003). 2005;45(5):566-72.

3. Gonzalez J, Noga M. Medication therapy management. J Manag Care Pharm. 2008;14(6 suppl S-c):S8-S11. Available at: http://www.amcp.org/ data/jmcp/Aug\%20suppl\%20C_S8-S11.pdf.

4. The Lewin Group. Medication therapy management services: a critical review. J Am Pharm Assoc (2003). 2005;45(5):580-87. Available at: http:// www.accp.com/docs/positions/commentaries/mtms.pdf. Accessed May 30, 2011

5. Medicare Prescription Drug, Improvement, and Modernization Act of 2003, Public Law 108-173, HRl (December 8, 2003). Available at: http:// www.cms.gov/MMAUpdate/downloads/hrl.pdf. Accessed May 30, 2011.

6. Centers for Medicare and Medicaid Services. Medicare Part D Medication Therapy Management (MTM) Programs: 2009 Fact Sheet. Updated July 21, 2009. Available at: https://www.cms.gov/PrescriptionDrugCovContra/ Downloads/MTMFactSheet2009.pdf. Accessed May 30, 2011.

7. Ernst FR, Grizzle AJ. Drug-related morbidity and mortality: updating the cost-of-illness model. J Am Pharm Assoc (Wash). 2001;41(2):192-99.

8. Johnson JA, Bootman JL. Drug-related morbidity and mortality. A cost-ofillness model. Arch Intern Med. 1995;155(18):1949-56.

9. Committee on Identifying and Preventing Medication Errors. Preventing Medication Errors: Quality Chasm Series. Washington DC: National Academies Press; 2007.

10. Bunting BA, Smith BH, Sutherland SE. The Asheville Project: clinical and economic outcomes of a community-based long-term medication therapy management program for hypertension and dyslipidemia. J Am Pharm Assoc (2003). 2008;48(1):23-31.

11. Ramalho de Oliveira D, Brummel AR, Miller DB. Medication therapy management: 10 years of experience in a large integrated health care system. J Manag Care Pharm. 2010;16(3):185-95. Available at: http://www.amcp.org/ data/jmcp/185-195.pdf.

12. Barnett MJ, Frank J, Wehring H, et al. Analysis of pharmacist-provided medication therapy management (MTM) services in community pharmacies over 7 years. J Manag Care Pharm. 2009;15(1):18-31. Available at: http:// www.amcp.org/data/jmcp/018-031.pdf.

13. Isetts BJ, Schondelmeyer SW, Artz MB, et al. Clinical and economic outcomes of medication therapy management services: the Minnesota experience. J Am Pharm Assoc (2003). 2008;48(2):203-11; 3 p following 211.

14. Pindolia VK, Stebelsky L, Romain TM, Luoma L, Nowak SN, Gillanders F. Mitigation of medication mishaps via medication therapy management. Ann Pharmacother. 2009;43(4):611-20.

15. Haxby DG, Weart CW, Goodman BW Jr. Family practice physicians' perceptions of the usefulness of drug therapy recommendations from clinical pharmacists. Am J Hosp Pharm. 1988;45(4):824-27.

16. Klopfer JD, Einarson TR. Acceptance of pharmacists' suggestions by prescribers: a literature review. Hosp Pharm. 1990;25(9):830-32, 834-36.

17. Carroll NV. Do community pharmacists influence prescribing? J Am Pharm Assoc (2003). 2003;43(5):612-21.

18. Brown DJ, Helling DK, Jones ME. Evaluation of clinical pharmacist consultations in a family practice office. Am J Hosp Pharm. 1979;36(7):912-15.

19. Carter BL, Helling DK. Ambulatory care pharmacy services: has the agenda changed? Ann Pharmacother. 2000;34(6):772-87. 
20. Singhal PK, Raisch DW, Gupchup GV. The impact of pharmaceutical services in community and ambulatory care settings: evidence and recommendations for future research. Ann Pharmacother. 1999;33(12):1336-55.

21. Bunting BA, Cranor CW. The Asheville Project: long-term clinical, humanistic, and economic outcomes of a community-based medication therapy management program for asthma. J Am Pharm Assoc (2003). 2006;46(2):133-47

22. Cranor CW, Bunting BA, Christensen DB. The Asheville Project: longterm clinical and economic outcomes of a community pharmacy diabetes care program. J Am Pharm Assoc (Wash). 2003;43(2):173-84.

23. Schommer JC, Planas LG, Johnson KA, Doucette WR. Pharmacistprovided medication therapy management (part 1): provider perspectives in 2007. J Am Pharm Assoc (2003). 2008;48(3):354-63.

24. Schommer JC, Planas LG, Johnson KA, Doucette WR. Pharmacistprovided medication therapy management (part 2): payer perspectives in 2007. J Am Pharm Assoc (2003). 2008;48(4):478-86.

25. DeName B, Divine H, Nicholas A, Steinke DT, Johnson CL. Identification of medication-related problems and health care provider acceptance of pharmacist recommendations in the DiabetesCARE program. J Am Pharm Assoc (2003). 2008;48(6):731-36.

26. Doucette WR, McDonough RP, Klepser D, McCarthy R. Comprehensive medication therapy management: identifying and resolving drug-related issues in a community pharmacy. Clin Ther. 2005;27(7):1104-11.

27. McCollum M, Nuffer W, Ellis SL, Turner CJ. Physician acceptance of pharmacotherapy recommendations made by pharmacy students in a rural pharmacy-based diabetes care and education clinic. Am J Pharm Educ. 2009;73(2):24. Available at: http://www.ncbi.nlm.nih.gov/pmc/articles/ PMC2690894/pdf/ajpe24.pdf. Accessed May 30, 2011

28. Von Muenster SJ, Carter BL, Weber CA, et al. Description of pharmacist interventions during physician-pharmacist co-management of hypertension. Pharm World Sci. 2008;30(1):128-35.

29. Chrischilles EA, Carter BL, Lund BC, et al. Evaluation of the Iowa Medicaid pharmaceutical case management program. J Am Pharm Assoc (2003). 2004;44(3):337-49.

30. Park JJ, Kelly P, Carter BL, Burgess PP. Comprehensive pharmaceutical care in the chain setting. J Am Pharm Assoc (Wash). 1996;NS36(7):443-51.

31. Hanlon JT, Weinberger M, Samsa GP, et al. A randomized, controlled trial of a clinical pharmacist intervention to improve inappropriate prescribing in elderly outpatients with polypharmacy. Am J Med. 1996;100(4):428-37.

32. Galt KA. Cost avoidance, acceptance, and outcomes associated with a pharmacotherapy consult clinic in a Veterans Affairs Medical Center. Pharmacotherapy. 1998;18(5):1103-11.
33. Mason JD, Colley CA. Effectiveness of an ambulatory care clinical pharmacist: a controlled trial. Ann Pharmacother. 1993;27(5):555-59.

34. Perera PN, Guy MC, Boesen KP. A telephone-based medication management therapy management (MTM) center: program development and observations over five years. Arizona Journal of Pharmacy. 2011;3(1):24-30. Available at: http://www.pharmacy.arizona.edu/sites/default/files/MMC\%20 Program\%20Description.pdf. Accessed May 30, 2011.

35. Weiner JP, Abrams C, Millman A, eds. The Johns Hopkins ACG System. Release notes. Version 8. Section 2. Johns Hopkins University School of Public Health. 2006. Available at: http://www.acg.jhsph.edu/ ACGDocuments/ACGSystemVersion80Release\%20Notes.pdf. Accessed May 30, 2011.

36. Strand LM, Cipolle RJ, Morley PC, Frakes MJ. The impact of pharmaceutical care practice on the practitioner and the patient in the ambulatory practice setting: twenty-five years of experience. Curr Pharm Des. 2004;10(31):3987-4001.

37. Van Der Sijs H, Aarts J, Vulto A, Berg M. Overriding of drug safety alerts in computerized physician order entry. J Am Med Inform Assoc. 2006;13(2):138-47. Available at: http://www.ncbi.nlm.nih.gov/pmc/articles/ PMC1447540/pdf/138.pdf. Accessed May 30, 2011.

38. Gambassi G, Forman DE, Lapane KL, et al. Management of heart failure among very old persons living in long-term care: has the voice of trials spread? The SAGE Study Group. Am Heart J. 2000;139(1 Pt 1):85-93.

39. McCormick D, Gurwitz JH, Goldberg RJ, et al. Prevalence and quality of warfarin use for patients with atrial fibrillation in the long-term care setting. Arch Intern Med. 2001;161(20):2458-63. Available at: http://archinte.amaassn.org/cgi/reprint/161/20/2458. Accessed May 30, 2011.

40. McGlynn EA, Asch SM, Adams J, et al. The quality of health care delivered to adults in the United States. N Engl J Med. 2003;348(26):263545. Available at: http://www.nejm.org/doi/full/10.1056/NEJMsa022615. Accessed May 30, 2011.

41. Sloane PD, Gruber-Baldini AL, Zimmerman S, et al. Medication undertreatment in assisted living settings. Arch Intern Med. 2004;164(18):2031-37. Available at: http://archinte.ama-assn.org/cgi/reprint/164/18/2031. Accessed May 30, 2011.

42. de Almeida Neto AC, Chen TF. When pharmacotherapeutic recommendations may lead to the reverse effect on physician decision-making. Pharm World Sci. 2008;30(1):3-8. Available at: http://www.ncbi.nlm.nih.gov/pmc/ articles/PMC2082656/pdf/11096_2007_Article_9143.pdf. Accessed May 30, 2011. 